\title{
In Vitro PIG-A Gene Mutation Assay in Human B-Lymphoblastoid TK6 Cells
}

\author{
Chang-Hui Zhou ${ }^{1 \#}$ Chun-Rong Yu ${ }^{1 \#}$ Peng-Cheng Huang ${ }^{1}$ Ruo-Wan Li ${ }^{1} \quad$ Jing-Ting Wang ${ }^{1}$ \\ Tian-Tian Zhao ${ }^{1}$ Ze-Hao Zhao ${ }^{1}$ jing $\mathrm{Ma}^{1 *}$ Yan Chang ${ }^{1 *}$
}

\author{
${ }^{1}$ Shanghai Innostar Bio-tech Co., Ltd., China State Institute of \\ Pharmaceutical Industry, Shanghai, People's Republic of China \\ Pharmaceut Fronts 2021;3:e77-e85.
}

\begin{abstract}
Address for correspondence Jing Ma, PhD, Shanghai Innostar Biotech Co., Ltd., 199 Guoshoujing Road, Pudong New Area, Shanghai 201203, People's Republic of China (e-mail: jingma2019@163.com).

Yan Chang, PhD, Shanghai Innostar Bio-tech Co., Ltd., 199 Guoshoujing Road, Pudong New Area, Shanghai 201203, People's Republic of China (e-mail: ychang@innostar.cn).
\end{abstract}

\begin{abstract}
Keywords

- PIG-A gene mutation assay

- flow cytometry

- TK6 cells

- genotoxicity
\end{abstract}

The X-linked PIG-A gene is involved in the biosynthesis of glycosylphosphatidylinositol (GPI) anchors. PIG-A mutant cells fail to synthesize GPI and to express GPI-anchored protein markers (e.g., CD59 and CD55). In recent years, in vitro PIG-A assay has been established based on the high conservation of PIG-A/Pig-a loci among different species and the large data from the in vivo system. The purpose of this study was to extend the approach for PIG-A mutation assessment to in vitro human B-lymphoblastoid TK6 cells by detecting the loss of GPI-linked CD55 and CD59 proteins. TK6 cells were treated with three mutagens 7,12-dimethylbenz[a]anthracene (DMBA), N-ethyl-N-nitrosourea (ENU), etoposide (ETO), and two nonmutagens: cadmium chloride $\left(\mathrm{CdCl}_{2}\right)$ and sodium chloride $(\mathrm{NaCl})$. The mutation rate of PIG-A gene within TK6 cells was determined on the 11th day with flow cytometry analysis for the negative frequencies of CD55 and CD59. The antibodies used in this production were APC mouse-anti-human CD19 antibody, PE mouse anti-human CD55 antibody, PE mouse anti-human CD59 antibody, and nucleic acid dye 7-AAD. An immunolabeling method was used to reduce the high spontaneous level of preexisting PIG-A mutant cells. Our data suggested that DMBA-, ENU-, and ETOinduced mutation frequency of PIG-A gene was increased by twofold compared with the negative control, and the effects were dose-dependent. However, $\mathrm{CdCl}_{2}$ and $\mathrm{NaCl}$ did not significantly increase the mutation frequency of PIG-A gene, with a high cytotoxicity at a dose of $10 \mathrm{mmol} / \mathrm{L}$. Our study suggested that the novel in vitro PIG-A gene mutation assay within TK6 cells may represent a complement of the present in vivo Pig-a assay, and may provide guidance for their potential use in genotoxicity even in cells with a significant deficiency of GPI anchor.

\section{Introduction}

Genotoxicity tests are utilized to identify compounds with a potential risk for carcinogenicity and heritable mutations,

$\overline{\#}$ These authors contributed equally to this work.

received

April 14, 2021

accepted

June 24,2021
DOI https://doi.org/

$10.1055 / \mathrm{s}-0041-1735146$ ISSN 2628-5088. which require a battery of tests to cover different genetic endpoints, such as DNA damage, gene mutation, as well as structural or numerical chromosomal abbreviation. ${ }^{1}$ Currently, a series of standard test battery has been adopted for the detection of mutagens, including bacterial reverse mutation assay (Ames test), in vivo transgenic gene mutation (c) 2021. The Author(s).

This is an open access article published by Thieme under the terms of the Creative Commons Attribution License, permitting unrestricted use, distribution, and reproduction so long as the original work is properly cited. (https://creativecommons.org/licenses/by/4.0/)

Georg Thieme Verlag KG, Rüdigerstraße 14, 70469 Stuttgart, Germany 
assay (such as Muta Mouse, BigBlue mice, etc.), and in vitro gene mutation assay of mammalian cell lines (ICH 2012). The overall aim of these test systems is to generate a solid database for hazard identification with respect to mutagenicity and to assess the mechanisms of action of chemical carcinogens.

Currently, mutation assay for a rodent-based endogenous phosphatidylinositol class A gene (PIG-A in humans and Pig- $a$ in rodents) has become a recognized method for detecting potential mutagenicity of exogenous compounds. ${ }^{2}$ The PIG-A/Pig-a gene is involved in early synthesis of cell-surface glycosylphosphatidylinositol (GPI) anchors, which was usually employed by GPI anchor proteins (e.g., CD59, CD55, or CD90) to bind to the cell membrane. Of all the genes involved in the GPI anchor synthesis, only the PIG-A/Pig- $a$ gene is located on the $\mathrm{X}$ chromosome. Therefore, in each cell, there is only one copy of the functional PIG-A/Pig- $a$ gene, and a single inactivating mutation in this gene will result in the inactivation of the enzymatic function of the PIG-A protein and the subsequent deficiency of all GPI-linked surface proteins. ${ }^{3,4}$

Flow cytometry is the most common method for diagnosis of GPI(-) frequency (PIG-A gene mutation rate) in TK6 human lymphoblastoid cells. ${ }^{5-9}$ From a throughput standpoint perspective, flow cytometry analysis of Pig- $a$ mutations may be useful for in vitro analysis of gene mutation and development of high-density dose-response data. ${ }^{10}$ Evidence suggests that an in vitro trial may also be conceived of as the value of testing hypotheses about the results of an in vivo assay (e.g., investigating negative in vivo responses) and of prescreening compounds for in vivo testing. ${ }^{11}$ Compared with the existing in vitro gene mutation assays (such as mouse lymphoma assay [MLA] test and hypoxanthine-guanine phosphoribosyl transferase [HPRT] gene mutation test), the in vitro PIG-A gene mutation test has the following three advantages: (1) being able to select human cells with complete function of P53 gene; (2) reducing the false-positive rate of in vitro genotoxicity test; and (3) shorter detection period (only 11 days) in comparison to MLA or HPRT gene mutation tests. Therefore, in vitro PIG-A gene mutation test using flow cytometry may be more objective, convenient, and high-throughput. ${ }^{9,12}$

TK6 cells, known as GPI-anchor-negative cells, grow in suspension, and have good practical usage in genotoxicity testing, and this may be attributed to its well-known characteristics for flow cytometric analysis, as well as the available access of the standardized cultures for genetic toxicological assessment from cell repositories. ${ }^{13-15}$ In this study, a simple and efficient immunomagnetic separation was explored in TK6 cells to obtain a relative low and stable GPI(-) background frequency. A PIG-A gene mutation assay was then conducted through flow cytometry assay for detecting the loss of GPI-linked CD55 and CD59 using mutagen and nonmutagenic compounds with different mechanisms of action. Our data suggested that the development and testing of methods for in vitro PIG-A gene mutation assay may represent a promising strategy to investigate the potential mutagenicity of chemical or physical mutagens.

\section{Materials and Methods}

\section{Reagents and Antibodies}

Human TK6 cells were purchased from American Type Culture Collection (ATCC; http://www.atcc.com); benzopyrene (B[a]P; Cat. No. B1760), ethyl methanesulfonate (EMS; Cat. No. M0880), N-ethyl-N-nitrosourea (ENU; Cat. No. N3385), etoposide (ETO; Cat. No. E1383), paraformaldehyde (Cat. No. 158127), 7,12-dimethylbenz[a]anthracene (DMBA; Cat. No. D3254), and sodium chloride ( $\mathrm{NaCl}$; Cat. No. S9888) were purchased from Sigma-Aldrich (United States); cadmium chloride $\left(\mathrm{CdCl}_{2}\right.$; Cat. No. C11634) was obtained from Aladdin (China); RPMI-1640 medium, heat-inactivated horse serum, phosphate buffer solution (PBS), antibiotics, and L-glutamine were purchased from Gibco (United States); bovine serum albumin (BSA; Cat. No. 69003433) was purchased from Sinopharm Chemical Reagent Co., Ltd. (China); APC mouse anti-human CD19 antibody (Cat. No. 561742), PE mouse anti-human CD55 antibody (Cat. No. 341030), PE mouse anti-human CD59 antibody (Cat. No. 560953), and nucleic acid dye 7-amino-actinomycin D (7-AAD; Cat. No. 561080) were obtained from BD Bioscience (United States); anti-PE microbeads (Cat. No. 130-048-801) and LS Separation columns (Cat. No. 130-042-401) were purchased from Miltenyi Biotec (Germany); actinomycin-D (Cat. No. SLD-1366) was obtained from Nanjing Sunlida Bio-tech Co., Ltd. (China); rat liver S9 was purchased from Moltox (United States); liver S9 cofactor was a stock solution prepared in the laboratory. The cytometer used was BD Accuri C6 PLUS (Becton-Dickinson, United States). The cell counter was Chemometec (NucleoCounter NC-100, Denmark).

\section{Cell Culture}

TK6 cells $\left(0.2 \times 10^{6}\right.$ or $10^{6}$ cells $\left./ \mathrm{mL}\right)$ were maintained in RPMI 1640 medium supplemented with $10 \%$ (v/v) heat-inactivated horse serum, $2 \mathrm{mmol} / \mathrm{L}$ L-glutamine, and antibiotics (penicillin at 20 units $/ \mathrm{mL}$ and streptomycin at $20 \mu \mathrm{g} / \mathrm{mL}$ ). The cells were cultured at $37^{\circ} \mathrm{C}$ with $5 \% \mathrm{CO}_{2}$ in an incubator.

\section{S9 Metabolic Activation System and Test Article Dose Formulation Preparation}

The mammalian liver post-mitochondrial fraction (S9) was purchased from Molecular Toxicology, Inc. (Moltox Inc., Boone, North Carolina, United States), which was prepared from male Sprague-Dawley rats that had been injected with Aroclor 1254 at $500 \mathrm{mg} / \mathrm{kg}$. The liver microsome enzyme system (S9 mixture) was the mixture of S9 and S9 cofactors containing NADP ( $4 \mathrm{mmol} / \mathrm{L})$, glucose-6-phosphate $(5 \mathrm{mmol} / \mathrm{L}), \mathrm{KCl}$ (30 mmol/L), $\mathrm{MgCl}_{2}(10 \mathrm{mmol} / \mathrm{L}), \mathrm{PBS}$ at $\mathrm{pH} 7.4$, and deionized water. The final concentration of S9 in the culture medium was $1.0 \%(\mathrm{v} / \mathrm{v})$.

\section{Antibody Labeling}

TK6 cells $\left(2 \times 10^{6}\right)$ were washed with PBS $(10 \mathrm{~mL})$, antibodylabeled in a total volume of $175 \mu \mathrm{L}$ staining solution (PBS with 2\% BSA, mouse anti-human CD19-APC [ $40 \mu \mathrm{L} /$ sample], mouse anti-human CD55-PE [24 $\mu \mathrm{L} /$ sample], and mouse anti-human CD59-PE [40 $\mu \mathrm{L} /$ sample]), and then incubated at room 
temperature for 30 minutes in the dark. After washing with staining buffer (PBS with $2 \% \mathrm{BSA}[\mathrm{w} / \mathrm{v}]$, precooled) $(1 \mathrm{~mL} \times 2)$, cell pellets were resuspended in $500 \mu \mathrm{L}$ DNA staining solution (PBS with 2\%BSA; 7-AAD for $2 \mu \mathrm{L} /$ sample) for 10 minutes on ice to exclude dead cells, and then centrifuged. The supernatant was discarded and cells were fixed in $600 \mu \mathrm{L}$ fixation buffer (PBS with $1 \%$ formaldehyde $[\mathrm{w} / \mathrm{v}]$ and $2.5 \mu \mathrm{g} / \mathrm{mL}$ AD). Cells were placed on ice before flow cytometry analysis. All solutions or buffer was kept on ice after preparation.

To ensure the accuracy, four samples of $2 \times 10^{6}$ TK6 cells were separately prepared and labeled with individual antibody staining solution for further 30 minutes of incubation in the dark. The staining solutions included staining buffer with mouse anti-human CD19-APC ( $20 \mu \mathrm{L} /$ sample), or staining buffer with mouse anti-human CD55-PE (12 $\mu \mathrm{L} /$ sample) and mouse anti-human CD59-PE ( $20 \mu \mathrm{L} /$ sample), or DNA staining solution. After completion, all samples were rinsed with staining buffer $(1 \mathrm{~mL} \times 2)$, and cells were fixed in $600 \mu \mathrm{L}$ fixation buffer and placed on ice before analysis.

\section{Flow Cytometry Assay for GPI(-) Frequency Analysis} All flow cytometric analyses were conducted with an Accuri C6 PLUS from Becton-Dickinson. Excitation and emission detection measurements of the applied fluorescence dyes were as follows: APC (640-670/14 nm) and PE (488-575/26 nm). Samples were analyzed with a middle rate or $65 \mu \mathrm{L} / \mathrm{min}$. For each determination of the GPI(-) frequency (PIG-A gene mutation rate), at least $10^{6}$ cells were collected.

\section{Cleansing of Preexisting CPI(-) TK6 Cells by Immunomagnetic Separation}

For cleansing of preexisting GPI(-) TK6 cells, $\sim 4 \times 10^{6}$ TK6 cells were pelleted at $200 \mathrm{~g}$ for 5 minutes and resuspended in $2 \mathrm{~mL}$ staining solution. The cells were labeled at room temperature for 30 minutes in the dark. After labeling, the cells were washed with staining buffer twice, and then pelleted at $200 \mathrm{~g}$ for 5 minutes. The cell pellets were resuspended in $500 \mu \mathrm{L}$ PBS (with $2 \%$ BSA and precooled) containing $40 \mu \mathrm{L}$ anti-PE microbeads for 30 minutes on ice or at 2 to $8^{\circ} \mathrm{C}$ protected from light. After incubation, the cells were washed by $10 \mathrm{~mL}$ staining buffer (precooled), and resuspended in $2 \mathrm{~mL}$ staining buffer (precooled). LS columns were placed in the MACS Separator and prewetted with a $5 \mathrm{~mL}$ staining buffer (precooled) in a biosafety cabinet. Then $2 \mathrm{~mL}$ cell suspension was added into the LS columns and the cells were allowed to freely flow through the column by gravity. After all of the suspension was run out, $5 \mathrm{~mL}$ staining buffer (precooled) was loaded onto the LS column for three times. Then the LS column was taken out from the separator and $5 \mathrm{~mL}$ staining buffer (precooled) was added. The cells adsorbed in the LS column were extruded with a piston and collected. The cell suspension was centrifuged at $200 \mathrm{~g}$ for 5 minutes. Pellet was resuspended in $10 \mathrm{~mL}$ culture medium for expansion culture. After expansion, GPI(-) frequency was analyzed by flow cytometry. If GPI(-) frequency of TK6 cells was too high, the above steps were repeated and performed the cleaning steps again.

\section{Determination of Doubling Times and Spontaneous Mutation Rate of TK6 Cells}

Preexisting GPI(-)-cleansed TK6 cells were named TK6 ${ }^{\mathrm{GPI}+}$ cells. For doubling time determination, $\mathrm{TK}^{\mathrm{GPI}+}$ cells were seeded in triplicate at a density of $10^{5}$ and $2 \times 10^{5}$ cells $/ \mathrm{mL}$ in a total volume of $25 \mathrm{~mL}$ medium. Cell growth was followed for 3 days by determining cell numbers every day. The doubling time was calculated according to Eq. (1):

$$
\text { D.T. }=\frac{\left(t_{2}-t_{1}\right) \times \log _{10} 2}{\log _{10} C h-\log _{10} C l}
$$

where D.T. is the doubling time, $t_{2}$ the cell harvest time, $t_{1}$ the cell inoculation time, $\mathrm{Ch}$ the cell harvest density, and $\mathrm{Ci}$ the cell inoculation density.

TK6 ${ }^{\mathrm{GPI}+}$ cells were cultured and passaged for 40 days and $10^{6}$ cells were subcultured in $25 \mathrm{~mL}$ RPMI- 1640 every 2 days. GPI(-) frequency was tested every 4 days, and every 8 days for the last two times. Based on the TK6 doubling time, the GPI(-) frequencies were plotted over the corresponding population doublings. After linear regression was applied (fit curve by GraphPad Prism 7), the resulting slope value was equivalent to the spontaneous mutation rate $(\mu)$ that was calculated according to Eq. (2):

$$
\mu=\frac{a \times 10^{-6} \times D . T}{24}
$$

(2)

where $\alpha$ is the slope of the fit curve, D.T. the doubling time of TK $6^{\mathrm{GPI}+}$ cell, and 24 the 24 hours.

\section{Optimized Cytotoxicity Determination}

The cytotoxicity of test chemicals was measured to design appropriate dose ranges for mutagenicity testing by relative increase in cell counts (RICC). Cell density was determined by cell counter methods and RICC was calculated at 24 and 48 hours in the group without S9. In the group with S9 (24 hour $-\mathrm{S} 9$ group), $\mathrm{TK}^{\mathrm{GPI}+}$ cells were treated with articles for 3 hours ( 3 hour + S9 group) and rinsed with $10 \mathrm{~mL}$ PBS twice followed by cell density determination at 24 and 48 hours. Treatments which showed RICC between 10 and $20 \%$ of control and lower at 24 and 48 hours were selected as the top concentrations. If not limited by cytotoxicity, $10 \mathrm{mmol} / \mathrm{L}$ or precipitate concentration was chosen as the top concentration. RICC was calculated according to Eq. (3):

$$
\text { RICC }\left(\text { control \%) }=\frac{\text { Cell Density }_{\text {treatment }}-3 \times 10^{5}}{\text { Cell Density }_{\text {correl }}-3 \times 10^{5}} \times 100\right.
$$

\section{Treatments}

All experiments were performed with GPI(-)-cleansed $\mathrm{TK}^{\mathrm{GPI}+}$ cells. In case of incubations, $\mathrm{TK}^{\mathrm{GPI}+}$ cells were seeded at $3 \times 10^{5}$ cells $/ \mathrm{mL}$ in $9.9 \mathrm{~mL}$ culture media in T25 flasks on day 1. A $100 \mu \mathrm{L}$ formulation of test articles, positive control $(200 \mu \mathrm{mol} / \mathrm{L}$ EMS or $8 \mu \mathrm{mol} / \mathrm{L}$ B $[a] \mathrm{P})$, or appropriate solvent control was added into the flasks drop by drop. The details of every test article are shown in -Table 1. Cell 
Table 1 Test article list

\begin{tabular}{|l|l|l|l|l|}
\hline Test chemical & Abb. & Cas No. & Molecular weight & Modes of action (MOA) \\
\hline Ethyl methanesulfonate & EMS & $62-50-0$ & 124.16 & Alkylating agent \\
\hline Benzo[a]pyrene & $\mathrm{B}[a] \mathrm{P}$ & $50-32-8$ & 252.31 & Forms bulky adducts \\
\hline 7,12-Dimethyl-benz $[a]$ anthracene & DMBA & $57-97-6$ & 256.34 & Forms bulky adducts \\
\hline Etoposide & ETO & $33419-42-0$ & 588.56 & DNA topoisomerase II inhibitors \\
\hline N-Ethyl- $N$-nitrosourea & ENU & $759-73-9$ & 117.11 & Alkylating agent \\
\hline Cadmium chloride & $\mathrm{CdCl} 2$ & $10108-64-2$ & 183.32 & Nongenotoxic carcinogen \\
\hline Sodium chloride & $\mathrm{NaCl}$ & $7647-14-5$ & 58.44 & Salt \\
\hline
\end{tabular}

suspension was mixed by gentle vortex. Cells were directly cultured for 24 hours at $37^{\circ} \mathrm{C}, 5 \% \mathrm{CO}_{2}$ in a humidified environment for the 24 hour - S9 group. Then, the cells were rinsed with PBS and resuspended with $10 \mathrm{~mL}$ medium after 3 hours of treatment and with a continuous culture for 24 hours for the 4 hour + S9 group. After 24 hours, cells were washed with PBS. A total of $2 \times 10^{6}$ cells were subcultured every 2 days in $25 \mathrm{~mL}$ culture medium to allow phenotype expression. On day 11 , flow cytometry was performed to detect $\mathrm{GPI}(-)$ frequencies.

\section{Test Result Evaluation Criteria}

The biological relevance of the results was carefully examined. The response was considered positive when the following conditions were met: the test agents induced a twofold increase over negative control in the frequency of $\mathrm{GPI}(-)$ cells in a dose-dependent manner with Microsoft excel 2007.

\section{Results and Discussion}

\section{Template of GPI(-) Frequency Analysis by Flow Cytometry}

The occurrence of GPI mutations is extremely rare, which requires very sensitive methods to detect. To achieve this, two independent GPI-anchored proteins, CD55 and CD59, were labeled. The GPI $(+)$ cells were separated from GPI(-) cells by staining CD55 and CD59 with PE-conjugated antibodies, and an APC-conjugated CD19 antibody was used to identify most of the TK6 cells as B-lymphocytes.

In this experiment, the gating procedure for flow cytometric analyses was set up using parallel samples and the results are presented in - Fig. 1. Cells were collected by FSC/SSC scatter plot (-Fig. 1A, gate cells) and agglomeration cells were excluded by gating in FSC-A versus FSC-H scatter plots ( - Fig. 1B, gate single cells). Dead cells were excluded via the uptake of 7-AAD, and healthy cells were collected (-Fig. 1C). Finally, GPI(+) and GPI(-) cells were separated. The GPI $(+)$ cells showed positive APC and PE-fluorescent signals and were presented in the upper right quadrant (-Fig. 1D). Cells with nonspecific events lacking the APC signal were presented in the upper left quadrant and lower left quadrant, and were excluded from analysis (-Fig. 1D). In this study, a total of $10^{6}$ APC-positive cells were collected to analyze the $\operatorname{GPI}(-)$ frequency.

\section{Cleansing of Preexisting GPI(-) TK6 Cells}

Flow cytometric analysis showed that the spontaneous mutation rate of the GPI(-) frequency in TK6 cells was $\sim 23.4 \%$ ( - Fig. 2A), which is a very high rate, and the basic mutation frequency of $\mathrm{GPI}(-)$ cells was reduced to $0.18 \%$ (-Fig. 2B) after being cleared by the first magnetic bead adsorption, and $13.5 \times 10^{-6}$ ( - Fig. 2 C) after the second clearance, suggesting that immunomagnetic separation is a very useful method to separate and cleanse the GPI(-) TK6 cells. The cells after cleansing of mutant $\mathrm{GPI}(-)$ cells are called TK6 $6^{\mathrm{GPI}+}$ cells.

\section{Doubling Time and Spontaneous Mutation Rate of TK6 ${ }^{\text {GPI }+}$ Cells}

Cell doubling time has a decisive influence on the efficiency of genotoxicity testing. A stable cell doubling time is also a sign of good cell status. Our result showed that TK6 ${ }^{\mathrm{GPI}+}$ cells had a doubling time of $15.5 \pm 1.2$ hours.

The spontaneous GPI(-) rate was determined by cell division in the culture. TK6 ${ }^{\mathrm{GPI}+}$ cells were tested for spontaneous $\mathrm{GPI}(-)$ rate up to 40 days, and the mean spontaneous $\operatorname{GPI}(-)$
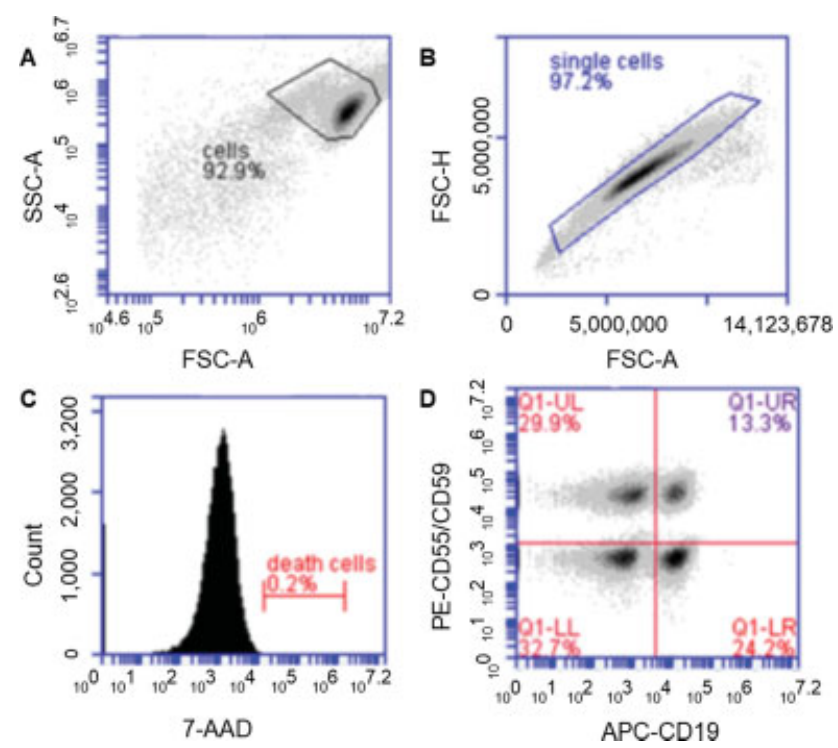

Fig. 1 TK6 cell detection template (parallel samples). (A) FSC-A versus SSC-A scatter plots for determining cell locations; (B) FSC-A versus FSC$\mathrm{H}$ scatter plots for exclusion adhesive cells; (C) histogram of FL-3 fluorescence channel, used to exclude necrotic and late apoptotic cells; (D) APC-CD19 versus PE-CD55 CD59 scatter plot, using crossgate to distinguish $\mathrm{GPI}(-)$ and $\mathrm{CD} 19(+)$ cells. 

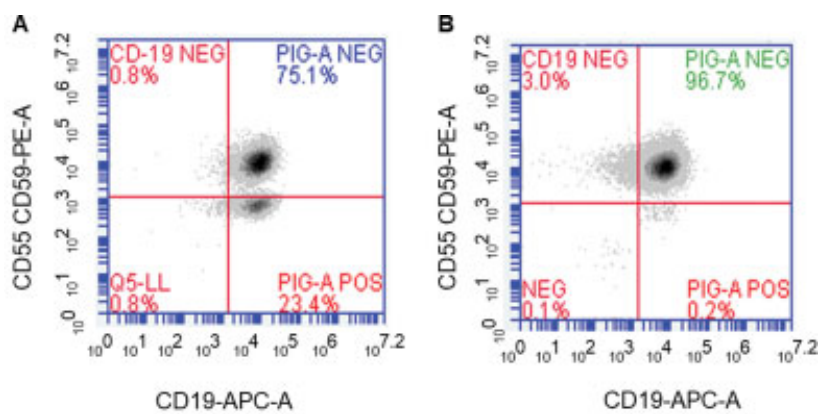

C

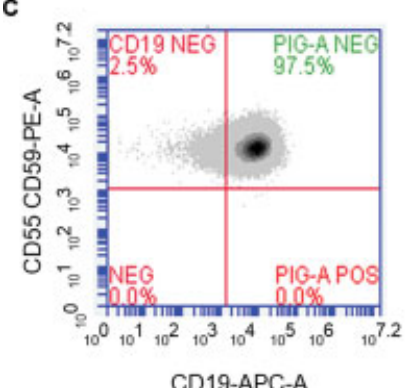

Fig. 2 Flow cytometric analysis of the background level of preexisting mutant cells. (A) Before the first cleansing; (B) after the first cleansing; (C) after the second cleansing. PIG-A NEG defines wild cells of PIG-A gene; PIG-A POS means the mutant cells of the PIG-A gene.

rate was $1.37 \times 10^{-6} /$ cell/generation for the $\mathrm{TK} 6^{\mathrm{GPI}+}$ cell line (fitted curve in - Fig. 3 ). This means that the mutation rate of TK6 cells increases by $\sim 22.2 \times 10^{-6}$ after 11 days of culture (doubling time of 15.5 hours). Therefore, we calibrated the tested mutation rate by subtracting the value of the spontaneous mutation in 11 days' culture $\left(22.2 \times 10^{-6}\right)$.

\section{Optimized Cytotoxicity Determination}

To detect the mutagenic effect, the dose of the treatment agents should be sufficiently high. However, the cytotoxici-

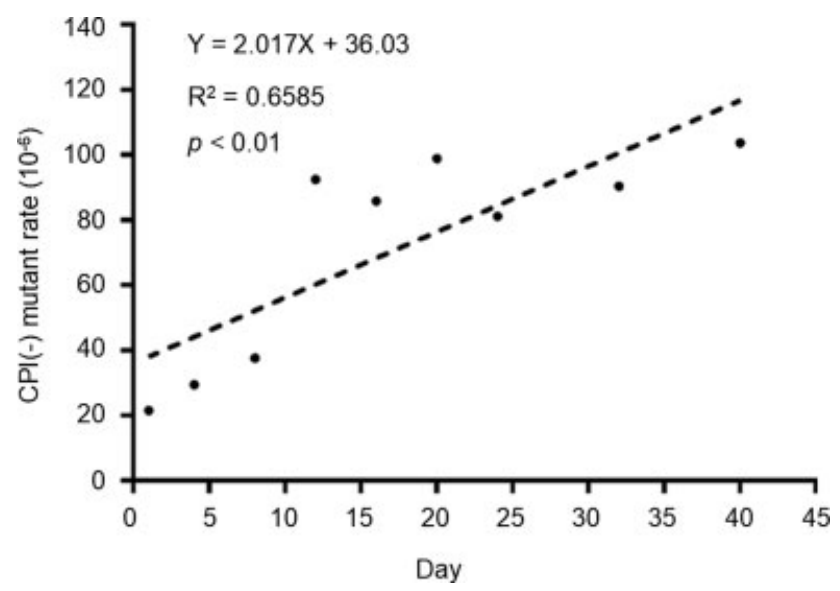

Fig. 3 Fitted curve of spontaneous GPI(-) gene mutation rates, where $\alpha=2.017$.

ty should not be less than $10 \%$ for the highest concentration, otherwise the cells could not be recovered in 11 days' culture. In our study, the doses were selected according to the higher RICC in 24 or 48 hours after cell exposure to the test agents (-Fig. 4 ). If a reduction of RICC was not limited up to $10 \mathrm{mmol} / \mathrm{L}$ or precipitation concentration, as in the case of $\mathrm{NaCl}, 10 \mathrm{mmol} / \mathrm{L}$ was selected as the highest concentration. The cytotoxicity of ETO, DMBA, and $\mathrm{CdCl}_{2}$ reached the maximum at 24 hours. Therefore, the concentrations of ETO and $\mathrm{CdCl}_{2}$ were selected based on the RICC of 24 hours. However, the concentrations of ENU were selected based on the RICC of 48 hours (-Table 2 ). Furthermore, the kinetics of RICC tested in 11 days' culture of all test articles (including EMS and $\mathrm{B}[a] \mathrm{P}$ as positive) were determined. Our data suggested that the trend of RICC initially rises, then falls, and finally returns gradually to normal level in 11 days (-Fig. 5).

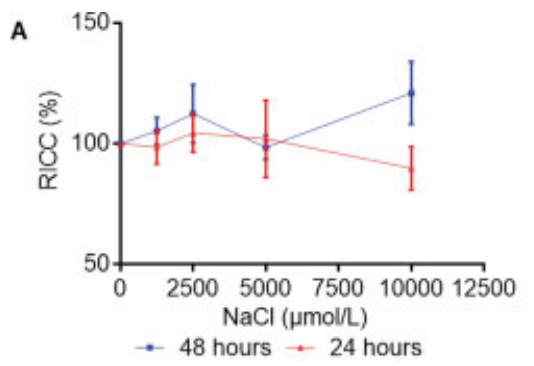

D

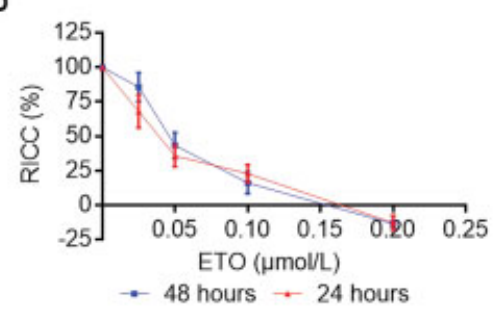

B

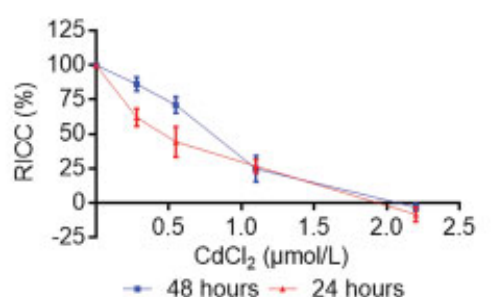

E

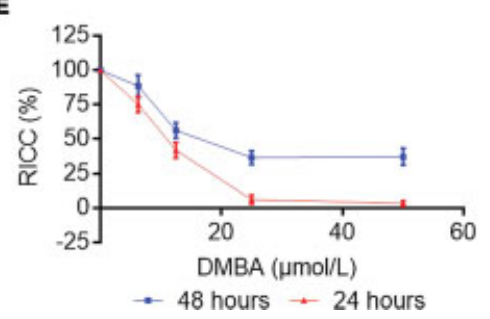

C

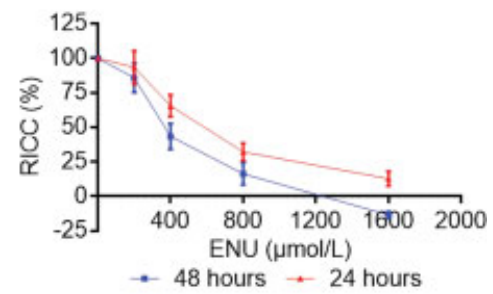

- 48 hours $\rightarrow 24$ hours

Fig. 4 The preliminary results of the dose range-finding study of the subjects with or without metabolic activation system. Pretest results of cytotoxicity of (A) NaCl; (B) $\mathrm{CdCl}_{2}$; (C) ENU; (D) ETO, and (E) DMBA. 
Table 2 Concentrations of test articles

\begin{tabular}{|l|l|l|l|l|}
\hline Test chemical & Abb. & Metabolic activation & Solvent & Test Con. $(\boldsymbol{\mu m o l} / \mathrm{L})$ \\
\hline Ethyl methanesulfonate & EMS & No & DMSO & $200^{\text {a }}$ \\
\hline Benzo[a]pyrene & B $[a] P$ & Yes & DMSO & $16^{\text {a }}$ \\
\hline 7,12-Dimethyl-benz[a]anthracene & DMBA & Yes & DMSO & $7.5,15,30$ \\
\hline Etoposide & ETO & No & $\mathrm{dH}_{2} \mathrm{O}$ & $0.0275,0.055,0.11$ \\
\hline N-Ethyl-N-nitrosourea & ENU & No & $\mathrm{dH}_{2} \mathrm{O}$ & $200,400,800$ \\
\hline Cadmium chloride & $\mathrm{CdCl} 2$ & No & $\mathrm{dH}_{2} \mathrm{O}$ & $0.55,1.1,2.2$ \\
\hline Sodium chloride & $\mathrm{NaCl}$ & No & $\mathrm{dH}_{2} \mathrm{O}$ & $1000,3160,10000$ \\
\hline
\end{tabular}

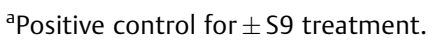

A

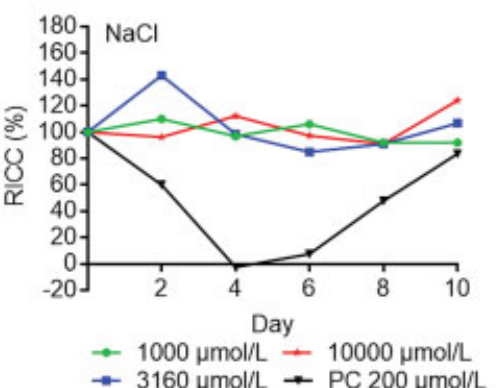

D

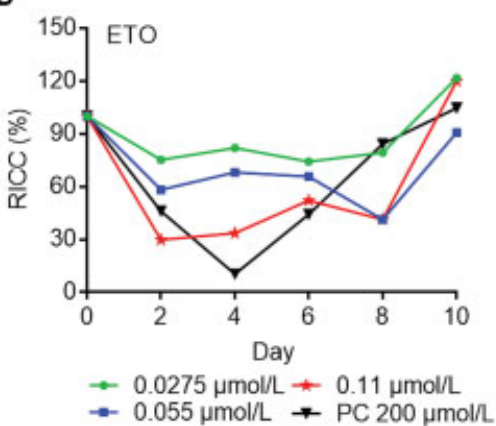

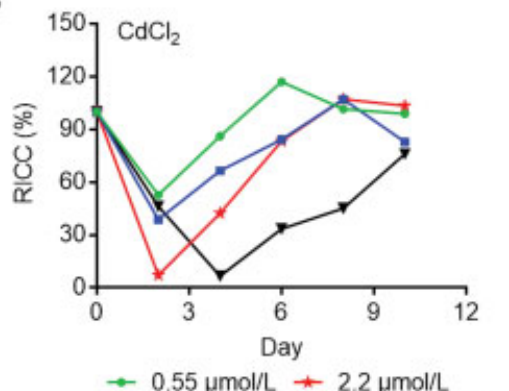

$\rightarrow 1.1 \mu \mathrm{mol} / \mathrm{L}+\mathrm{PC} 200 \mu \mathrm{mol} / \mathrm{L}$

E

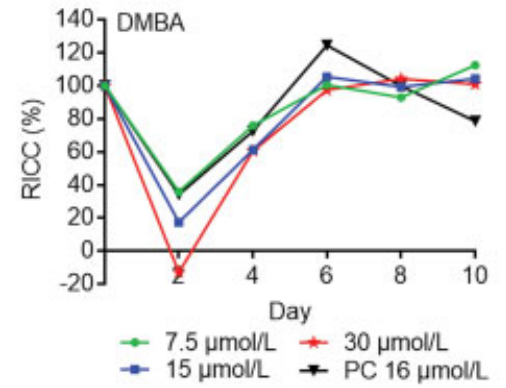

c

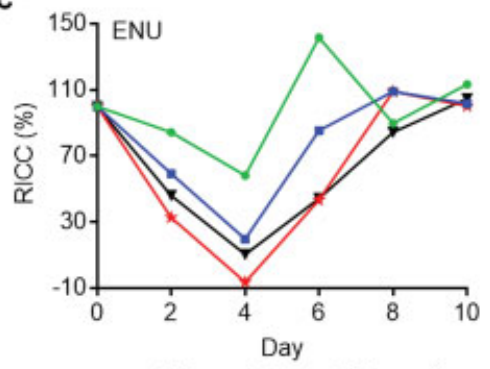

$\rightarrow 200 \mu \mathrm{moll} / \mathrm{L} \rightarrow 800 \mu \mathrm{mol} / \mathrm{L}$

- $400 \mu \mathrm{mol} / \mathrm{L} \rightarrow$ PC $200 \mu \mathrm{mol} / \mathrm{L}$

Fig. 5 The RICC of day 2-day 10 for test articles with or without a metabolic activation system. (A) NaCl; (B) CdCl ; (C) ENU; (D) ETO; (E) DMBA. $\mathrm{PC}$ (positive control) of $200 \mu \mathrm{mol} / \mathrm{L}$ EMS (24 hour - S9) and $16 \mu \mathrm{mol} / \mathrm{L} \mathrm{B[a]P}$ (4 hour + S9). RICC, relative increase in cell counts.

\section{Effect of Chemicals on PIG-A Mutation}

\section{Negative and Positive Effects}

Four experiments were performed in this study with $1 \%(\mathrm{v} / \mathrm{v})$ dimethylsulfoxide (DMSO) or deionized water as negative control and $200 \mu \mathrm{mol} / \mathrm{L}$ EMS (24 hour - S9) or $16 \mu \mathrm{mol} / \mathrm{L} \mathrm{B}[a]$ $\mathrm{P}(4$ hour $+\mathrm{S} 9)$ as positive control. The PIG-A mutation rate of the negative control groups ranged from 67.6 to $75 \times 10^{-6}$ with an average of $71.4 \times 10^{-6}$, while the PIG-A mutation rate of the positive control groups ranged from 142.3 to $282.6 \times 10^{-6}$ with an average of $228.2 \times 10^{-6}$. The high variability of the positive control groups may be attributed to the test article or manipulation (-Fig. 6 ).

Sodium chloride ( $\mathrm{NaCl}$ ): $\mathrm{NaCl}$ is a commonly used inorganic salt and a known nongenotoxic compound selected as a negative test article. $\mathrm{NaCl}$ was not cytotoxic to TK6 $6^{\mathrm{GPI}+}$ cells

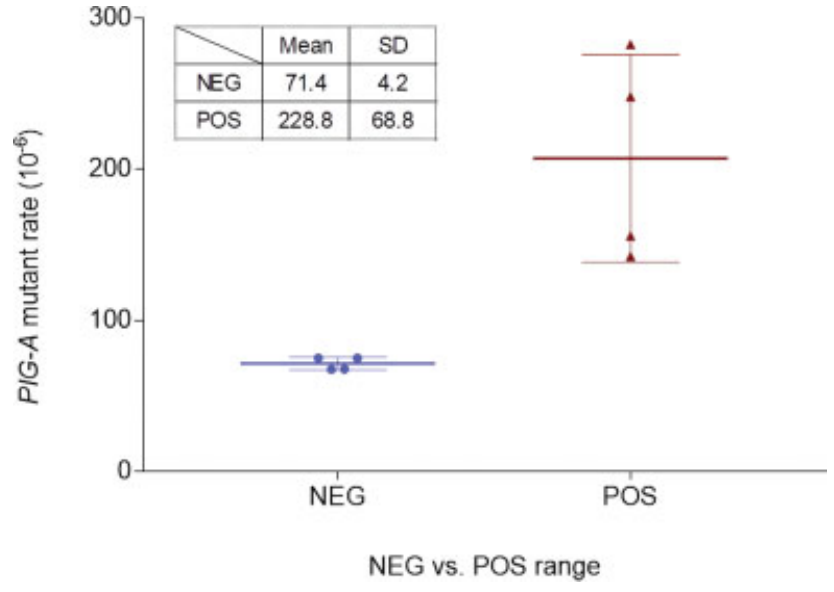

Fig. 6 PIG-A mutation ranger of negative and positive in this study. 


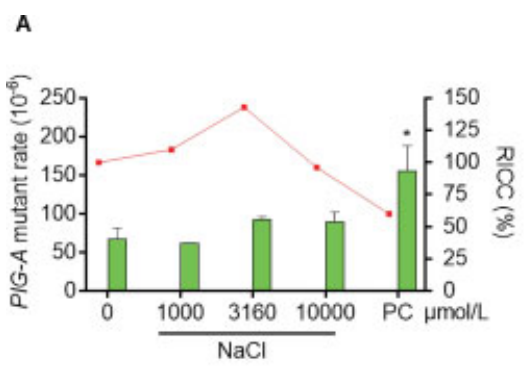

- RICC (\%) $\square$ PIG-A mutant rate $\left(10^{-6}\right)$

D

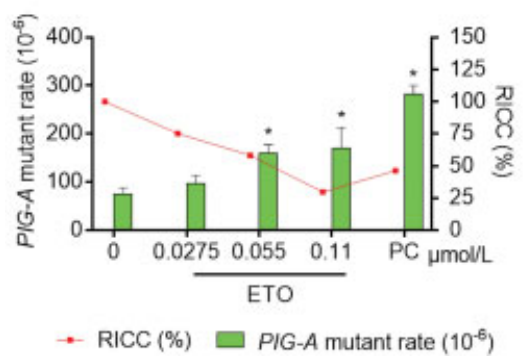

B

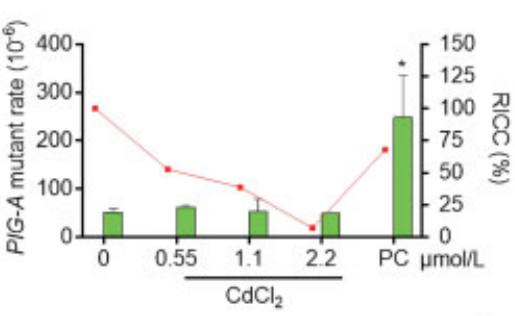

- RICC (\%) $\square$ PIG-A mutant rate $\left(10^{-6}\right)$
C

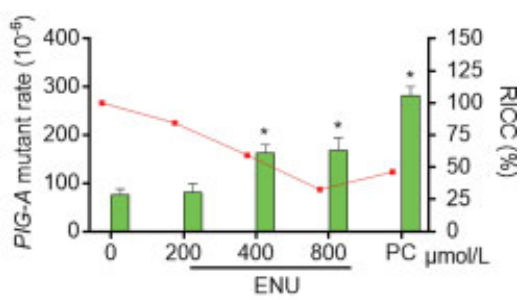

- RICC (\%) $\square$ PIG-A mutant rate $\left(10^{-6}\right)$

E

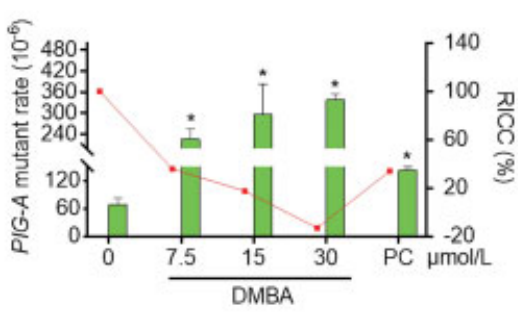

$\rightarrow \operatorname{RICC}(\%) \square$ PIG-A mutant rate $\left(10^{-6}\right)$

Fig. 7 Chemicals with or without metabolic activation system. In vitro PIG-A gene mutation detection results of (A) NaCl; (B) CdCl ${ }_{2}$; (C) ENU; (D) ETO; and (E) DMBA. PC: positive control $200 \mu \mathrm{mol} / \mathrm{L}$ EMS (24 hour - S9) and $16 \mu \mathrm{mol} / \mathrm{L}$ B[a]P (4 hour + S9). ${ }^{*}$ PIG-A gene mutation rate represents at least a twofold increase compared with the negative control.

and the solubility of $\mathrm{NaCl}$ in the medium was higher than $10 \mathrm{mmol} / \mathrm{L}$, so the highest concentration of $\mathrm{NaCl}$ was selected as $10 \mathrm{mmol} / \mathrm{L}$. In this experiment with the treatment without in vitro - $\mathrm{S} 9$ for 24 hours, $\mathrm{NaCl}$ did not cause a concentration correlation of the PIG-A gene mutation rate ( $\mathbf{- F i g}$. 7). The results of this $\mathrm{NaCl}$ were classified as negative in this experiment, consistent with the results of Ames and MLA tests for $\mathrm{NaCl}^{16}$

$\boldsymbol{N}$-nitroso-N-ethylurea (ENU): ENU acts as a potent alkylating agent of the nitrosourea class and it is a direct mutagenic agent that does not require metabolic activation. ${ }^{17}$ ENU is known to induce transitions and reversals after $\mathrm{O}^{2-}$ and $\mathrm{O}^{4-}$ alkylation of thymine residues and $\mathrm{O}^{6-}$ alkylation of guanine residues. ${ }^{18}$ ENU was positive under mouse lymphoma TK gene mutation assay (MLA) test and HPRT gene mutation test in the absence of S9 conditions. In this experiment, 400 and $800 \mu \mathrm{mol} / \mathrm{L}$ of ENU induced a concentration-dependent increase of PIG-A gene mutation rate in TK6 $6^{\mathrm{GPI}+}$ cells and more than twofold of the negative control (-Fig. 7), which was a positive result and was consistent with the published results of in vivo/in vitro PIG-A mutation assays. ${ }^{7}$

Etoposide (ETO): ETO is a topoisomerase II inhibitor that, upon entry into the nucleus, forms a drug-enzyme-DNA complex with DNA that interferes with DNA topoisomerase II, resulting in irreparable DNA damage. ${ }^{19,20}$ ETO was classified as a carcinogen (group 2A) that may be carcinogenic to humans by International Agency for Research on Cancer (IARC). In in vitro genotoxicity studies, ETO was weakly positive for strain TA98 in the Ames test, induced high frequency of small and large colony mutants in the MLA test, and induced chromosomal structural aberrations in the chromosomal aberration test. ${ }^{21,22}$ In the present experiments, the PIG- $A$ gene mutations in TK6 cells induced by 0.055 and $0.11 \mu \mathrm{mol} / \mathrm{L}$ of ETO were more than twofold higher than those in negative controls under conditions without metabolic activation system and with a dose-related manner in the absence of the S9-mix ( - Fig. 7), confirming the roles of ETO as a mutagen.

Cadmium chloride $\left(\mathbf{C d C l}_{2}\right): \mathrm{CdCl}_{2}$ is a cadmium heavy metal salt, and IARC classifies cadmium and cadmium-like compounds as Class I carcinogens (possibly carcinogenic to humans). ${ }^{22}$ However, studies on $\mathrm{CdCl}_{2}$ have found that it is not a direct DNA-acting agent, and the possible carcinogenic mechanism of $\mathrm{CdCl}_{2}$ is to stimulate and promote cell division by inhibiting DNA repair mechanisms and upstream signals of apoptosis through epigenetic pathways. ${ }^{23}$ The Ames test of $\mathrm{CdCl}_{2}$ had both negative and positive results (without S9 metabolism), while the results of the Bhas42 cell transformation assay of $\mathrm{CdCl}_{2}$ suggested that $\mathrm{CdCl}_{2}$ is a cancer promoter and noninitiator. ${ }^{24}$ Our data showed that a high cytotoxicity with RICC of $7.2 \%$ was induced by $2.2 \mu \mathrm{mol} / \mathrm{L}$ of $\mathrm{CdCl}_{2}$ (-Fig. 7). However, no significant and concentrationdependent increase was noted at all tested concentrations of $\mathrm{CdCl}_{2}$ in the $P I G-A$ gene mutation rate. Thus, $\mathrm{CdCl}_{2}$ was tested as a nonmutagen in this experiment.

7,12-dimethyl-benz[a] anthracene (DMBA): DMBA is a polycyclic aromatic hydrocarbon that is oxidized by $\mathrm{P} 450$ enzymes (CYP1A1 and 1B1) to form DNA adducts covalently with DNA, which can lead to DNA damage and gene mutations. DMBA is commonly used in animal tests to induce skin and mammary tumors, as well as leukemia and other 
tumors. ${ }^{25} \mathrm{~A}$ significant and concentration-dependent increase was noted in the PIG-A gene mutation rate in TK6 cells at concentrations of 7.5,15, and $30 \mu \mathrm{mol} / \mathrm{L}$ DMBA in the presence of 59-mix (-Fig. 7), suggesting that DMBA is a mutagen, which is consistent with the published findings.

\section{Conclusions}

The aim of this study was to develop an in vitro PIG-A gene mutation assay in TK6 cells via detection of the loss of GPIlinked CD55 and CD59 proteins by flow cytometry. Since mutations occur at a low frequency, the sensitivity of mutation detection methods is particularly important. To establish a highly sensitive PIG- $A$ gene mutation assay, cleansing of preexisting GPI(-) TK6 cells was performed, and TK6 ${ }^{\mathrm{GPI}+}$ cells were obtained by immunomagnetic sorting. Subsequently, the doubling time and spontaneous mutation rate of $\mathrm{TK}^{\mathrm{GPI}+}$ cells were characterized. We reduced the effect of the spontaneous mutation rate on the sensitivity of the assay by controlling the subculture time for $\mathrm{TK}^{\mathrm{GPI}+}$ cells that had a higher spontaneous mutations rate. We also found that RICC was important in the assay, with some compounds showing greater differences in RICC at 24 and 48 hours. If we selected the RICC at 24 hours as the concentration selection criterion, some chemicals may induce all cells to die on day 4 or 5 of the formal assay. ENU, ETO, DMBA, $\mathrm{CdCl}_{2}$, and $\mathrm{NaCl}$ were selected as subjects to validate the in vitro PIG-A assay, and they showed a positive result that each result of test articles was as expected.

TK6 cells have a normal P53 status which contributes to the maintenance of genomic integrity through recombinational repair. ${ }^{26}$ The TK6 cell line is mainly used in in vitro mammalian cell gene mutation tests using the thymidine kinase gene. The mutagens (X-rays, EMS, methyl methanesulfonate, and mitomycin $\mathrm{C}$ ) have been proved to dosedependently induce TK mutations in TK6 cells. ${ }^{27}$ In contrast to the low spontaneous mutation frequency of TK mutation, the spontaneous mutation frequency of PIG-A mutation was high, and it still elevated during culture after cleansing of preexisting GPI(-) cells. Therefore, the passage time of TK6 cells should be controlled within 4 weeks. Besides the PIG-A mutations, PIG- $L$ mutations also cause GPI-deficient isolates in the TK6 cell line, as PIG-L is heterozygous in these cells. ${ }^{28}$ Thus, although the TK6 cell assay may not be totally analogous to the in vivo Pig-a assay, it has been shown that the sensitivity of the TK6 cell assay may benefit from having both an X-linked and an autosomal reporter of mutation in terms of increasing the types of mutations that the assay can detect.

In summary, an in vitro PIG-A gene mutation detection method based on flow cytometry and a TK6 ${ }^{\mathrm{GPI}+}$ cell line was successfully established and preliminarily validated in this study. The method uses automated flow cytometry analysis to achieve high-throughput detection. The in vitro PIG-A gene mutation assay has a shorter experimental period and is relatively simple to perform in comparison to MLA assay and HPRT gene mutation assay. Therefore, the in vitro PIG- $A$ mutation assay is expected to complement the in vivo Pig$a$ assay with some distinct advantages compared with other in vitro mammalian mutagenicity tests.

\section{Funding}

This study was financially supported by the Major Projects Foundation of the National Health Commission of the People's Republic of China (Grant No. 2018ZX09201017008).

\section{Conflict of Interest}

The authors declare that they have no conflict of interest.

\section{References}

1 Cimino MC. Comparative overview of current international strategies and guidelines for genetic toxicology testing for regulatory purposes. Environ Mol Mutagen 2006;47(05):362-390

2 Miyata T, Takeda J, Iida Y, et al. The cloning of PIG-A, a component in the early step of GPI-anchor biosynthesis. Science 1993;259 (5099):1318-1320

3 Zurzolo C, Simons K. Glycosylphosphatidylinositol-anchored proteins: membrane organization and transport. Biochim Biophys Acta 2016;1858(04):632-639

4 Kinoshita T. Biosynthesis and deficiencies of glycosylphosphatidylinositol. Proc Jpn Acad, Ser B, Phys Biol Sci 2014;90(04):130-143

5 Krüger CT, Hofmann M, Hartwig A. The in vitro PIG-A gene mutation assay: mutagenicity testing via flow cytometry based on the glycosylphosphatidylinositol (GPI) status of TK6 cells. Arch Toxicol 2015;89(12):2429-2443

6 Rees BJ, Tate M, Lynch AM, et al. Development of an in vitro PIG-A gene mutation assay in human cells. Mutagenesis 2017;32(02): 283-297

7 Bemis JC, Avlasevich SL, Labash C, et al. Glycosylphosphatidylinositol (GPI) anchored protein deficiency serves as a reliable reporter of Pig-a gene mutation: Support from an in vitro assay based on L5178Y $/ \mathrm{Tk}^{+/-}$cells and the CD90.2 antigen. Environ Mol Mutagen 2018;59(01):18-29

8 Wang Y, Revollo J, McKinzie P, et al. Establishing a novel Pig-a gene mutation assay in L5178YTk ${ }^{+/-}$mouse lymphoma cells. Environ Mol Mutagen 2018;59(01):4-17

9 David R, Talbot E, Allen B, Wilson A, Arshad U, Doherty A. The development of an in vitro Pig-a assay in L5178Y cells. Arch Toxicol 2018;92(04):1609-1623

10 Johnson GE, Slob W, Doak SH, et al. New approaches to advance the use of genetic toxicology analyses for human health risk assessment. Toxcol Res 2015;4:667-676

11 Bemis JC, Heflich RH. In vitro mammalian cell mutation assays based on the Pig-a gene: a report of the International Workshops on Genetic Toxicology (IWGT) workgroup. Mutat Res Genet Toxicol Environ Mutagen 2019;847:403039

12 Ellis P, Fowler P, Booth E, et al. Where will genetic toxicology testing be in 30 years' time? Summary report of the 25th Industrial Genotoxicity Group Meeting, Royal Society of Medicine, London, November 9, 2011. Mutagenesis 2014;29(01):73-77

13 OECD iLibrary. OECD Guideline for the testing of chemicals, Section 4. In vitro mammalian cell gene mutation tests using the Hprt and xprt genes. Accessed July 2, 2021 at: https://www.oecd-ilibrary.org/ docserver/9789264264809-en.pdf?expires=1624388874\&id=id\&accname=guest\&checksum=48AA31AD17D5DC66BB8E902FEAC0F0D3.

14 OECD iLibrary. OECD Guideline for the testing of chemicals, secton 4. In vitro mammalian cell gene mutation tests using the Thymidine Kinase gene. Accessed July 2, 2021 at: https://www.oecd-ilibrary.org/docserver/9789264264908-en.pdf?expires=1624388821\&id=id\&accname=guest\&checksum=655A70F3F7AB4229B6E026174C446532

15 Lorge E, Moore MM, Clements J, et al. Standardized cell sources and recommendations for good cell culture practices in genotoxicity testing. Mutat Res 2016;809:1-15

16 Kirkland D, Kasper P, Müller L, Corvi R, Speit G. Recommended lists of genotoxic and non-genotoxic chemicals for assessment of 
the performance of new or improved genotoxicity tests: a followup to an ECVAM workshop. Mutat Res 2008;653(1-2):99-108

17 Kimoto T, Horibata K, Miura D, et al. The PIGRET assay, a method for measuring Pig-a gene mutation in reticulocytes, is reliable as a short-term in vivo genotoxicity test: summary of the MMS/JEMScollaborative study across 16 laboratories using 24 chemicals. Mutat Res 2016;811:3-15

18 Zielenska M, Beranek D, Guttenplan JB. Different mutational profiles induced by N-nitroso-N-ethylurea: effects of dose and error-prone DNA repair and correlations with DNA adducts. Environ Mol Mutagen 1988;11(04):473-485

19 Ezoe S. Secondary leukemia associated with the anti-cancer agent, etoposide, a topoisomerase II inhibitor. Int J Environ Res Public Health 2012;9(07):2444-2453

20 van Maanen JM, Lafleur MV, Mans DR, et al. Effects of the orthoquinone and catechol of the antitumor drug VP-16-213 on the biological activity of single-stranded and double-stranded phi X174 DNA. Biochem Pharmacol 1988;37(19):3579-3589

21 Ashby J, Tinwell H, Glover P, et al. Potent clastogenicity of the human carcinogen etoposide to the mouse bone marrow and mouse lymphoma L5178Y cells: comparison to Salmonella responses. Environ Mol Mutagen 1994;24(01):51-60

22 Suzuki H, Nakane S. Differential induction of chromosomal aberrations by topoisomerase inhibitors in cultured Chinese hamster cells. Biol Pharm Bull 1994;17(02):222-226
23 Kirkland D, Kasper P, Martus HJ, et al. Updated recommended lists of genotoxic and non-genotoxic chemicals for assessment of the performance of new or improved genotoxicity tests. Mutat Res Genet Toxicol Environ Mutagen 2016;795:7-30

24 Sakai A, Sasaki K, Muramatsu D, et al. A Bhas 42 cell transformation assay on 98 chemicals: the characteristics and performance for the prediction of chemical carcinogenicity. Mutat Res 2010; 702(01):100-122

25 Han EH, Hwang YP, Jeong TC, Lee SS, Shin JG, Jeong HG. Eugenol inhibit 7,12-dimethylbenz[a]anthracene-induced genotoxicity in MCF-7 cells: Bifunctional effects on CYP1 and NAD(P)H:quinone oxidoreductase. FEBS Lett 2007;581(04):749-756

26 Honma M, Hayashi M, Sofuni T. Cytotoxic and mutagenic responses to X-rays and chemical mutagens in normal and p53mutated human lymphoblastoid cells. Mutat Res 1997;374(01): 89-98

27 Honma M, Momose M, Tanabe H, et al. Requirement of wild-type p53 protein for maintenance of chromosomal integrity. Mol Carcinog 2000;28(04):203-214

28 Nicklas JA, Carter EW, Albertini RJ. Both PIGA and PIGL mutations cause GPI-a deficient isolates in the Tk6 cell line. Environ Mol Mutagen 2015;56(08):663-673 